\title{
Hookworm infection in infants: a case report and review of literature
}

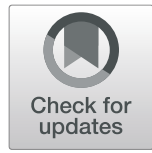

\author{
G. Umbrello ${ }^{1 *}$, R. Pinzani ${ }^{2}$, A. Bandera ${ }^{1,2}$, F. Formenti ${ }^{3,4}$, G. Zavarise $^{5}$, M. Arghittu ${ }^{6}$, D. Girelli ${ }^{2}$, A. Maraschini ${ }^{2}$, \\ A. Muscatello' ${ }^{2}$ P. Marchisio ${ }^{1,2}$ and S. Bosis ${ }^{2}$
}

\begin{abstract}
Background: Hookworm infections (Necator americanus, Ancylostoma duodenale) are common in rural areas of tropical and subtropical countries. Human acquisition results from direct percutaneous invasion of infective larvae from contaminated soil.

Overall, almost 472 million people in developing rural countries are infected. According to simulation models, hookworm disease has a global financial impact of over US\$100 billion a year. Hookworm infection in newborn or infancy is rare, and most of the cases reported in literature are from endemic countries.

Here, we describe the case of an infant with an Ancylostoma duodenale infection and review the literature currently available on this topic.
\end{abstract}

Case presentation: An Italian 2-month-old infant presented with vomit and weight loss. Her blood exams showed anemia and eosinophilia and stool analysis resulted positive for hookworms' eggs, identified as Ancylostoma duodenale with real time-PCR. Parasite research on parents' stools resulted negative, and since the mother travelled to Vietnam and Thailand during pregnancy, we assumed a transplacental transmission of the infection. The patient was treated successfully with oral Mebendazole and discharged in good conditions.

Discussion: Hookworm helminthiasis is a major cause of morbidity in children in the tropics and subtropics, but rare in developed countries.

Despite most of the patients is usually asymptomatic, children are highly exposed to negative sequelae such as malnutrition, retarded growth and impaired cognitive development. In infants and newborns, the mechanism of infection remains unclear. Although infrequent, vertical transmission of larvae can occur through breastfeeding and transplacentally. Hookworm infection should be taken into account in children with abdominal symptoms and unexplained persistent eosinophilia. The treatment of infants infected by hookworm has potential benefit, but further studies are needed to define the best clinical management of these cases.

\section{Background}

Hookworms are nematode parasites responsible for different clinical disorders. They belong to the helminthic family Ancylostomatidae, a part of the Strongyloidea superfamily. Human acquisition occurs via ingestion of eggs and/or skin contact with infectious larvae in moist contaminated soil, therefore in public health terms they

\footnotetext{
* Correspondence: giulia.umbrello@unimi.it

${ }^{1}$ Università degli Studi di Milano, Milan, Italy

Full list of author information is available at the end of the article
}

are known as soil-transmitted helminths (STH) [1]. Worldwide, Ancylostoma duodenale and Necator americanus are the two primary intestinal species, but more recently Ancylostoma ceylanicum has emerged as an important human parasite in some countries [2].

The prevalence of hookworm infection is affected by climatic and socioeconomic factors and represents a significant burden for public health in tropical and subtropical countries [3]. Overall, almost 472 million people in developing rural countries are infected, with the vast 
majority of cases occurring in South-East Asia and SubSaharan Africa [1, 4]. According to simulation models, hookworm disease is globally responsible for $>4$ million disability-adjusted life years (DALY) lost annually, with a financial impact of over US\$100 billion a year [5].

Infection prevalence typically rises with increasing age and reaches a plateau in young adults, indeed evidence from China and Southeast Asia shows that the highest prevalence is found among middle-aged subjects [6]. In the pediatric population, hookworm infection typically spreads among children when they start to crawl or walk. In newborn or infancy, on the contrary, it is rare, and most of the cases reported in literature are from tropical and subtropical countries, especially Nepal, China, India, and Africa [7-10].

Here we describe the case of a healthy Italian 2month-old infant with an Ancylostoma duodenale infection. We also review literature reports of hookworm infection in children, in order to discuss the main clinical findings and the diagnostic and therapeutic approach for this condition.

\section{Case presentation}

A two-month-old, Italian, exclusively breast-fed female was admitted to our Emergency Room for vomiting and weight loss. There was no history of fever, jaundice or abdominal distension.

One month before the admission, she was hospitalized for the same symptoms in a different Hospital. At that time, she was tested with blood and urine culture, blood exams including ammonium concentration, abdomen ultrasound and Rotavirus/Adenovirus faecal antigens. All the investigations were negative, except for the detection of eosinophilia (eosinophils count: 2900/ $\mu$ l). During the first hospitalization, she developed a mild diarrhoea, which was treated with probiotics, and after 4 days she was discharged in good health condition.

Upon presentation to our Clinic, the parents reported a 70 days-journey to South-East Asia (Vietnam and Thailand) during the first trimester of pregnancy, where the mother had presented several episodes of nausea and vomiting, attributed to pregnancy.

On physical examination, the infant was hemodynamically stable, alert and appropriate for age. She was well appearing and well-nourished. The abdomen was soft, and the rest of systemic examination was within normal limits. Physical findings were as follows: body weight $4.75 \mathrm{~kg}$; height $60 \mathrm{~cm}$; heart rate 120 beats/ min; body temperature $36^{\circ} \mathrm{C}$; oxygen saturation in room air $96 \%$; blood pressure $70 / 52 \mathrm{mmHg}$. On admission to our Hospital, the laboratory tests showed a white blood cell count of $19,060 / \mu \mathrm{l}$ with $27.1 \%$ of eosinophils (5170/ $\mu \mathrm{l})$, platelets count $756,000 / \mu \mathrm{l}$, haemoglobin $9.1 \mathrm{~g} / \mathrm{dl}$, peripheral smear showed microcytic hypochromic red blood cells (RBCs). Given the hemoglobin levels, an oral supplementation with iron and folic acid was started. Electrolytes, renal function and coagulation tests were within the normal range. Serum proteins, albumin, bilirubin and liver enzymes were normal; C-reactive protein (CRP) was negative. The abdomen ultrasound was normal; urinary culture was negative. Grossly, stools looked normal, with no blood appearance or melena; viral antigen and bacterial culture were negative.

The microscopic examination of stools detected the presence of hookworm's eggs which were confirmed in three different samples from different days (Fig. 1). The collected specimens were subsequently sent to the specialist parasitology laboratory of "Ospedale Sacro Cuore Don Calabria" of Negrar, where were tested with molecular biology techniques (Real Time polymerase chain reaction, RT-PCR) which confirmed the species as Ancylostoma duodenale. Parasitic research on parents' stools resulted negative, suggesting a possible vertical transmission of Ancylostoma infection during pregnancy. The infant was treated with oral Mebendazole $(100 \mathrm{mg} / \mathrm{die}$ in two doses) for 3 days, which was well tolerated, without any complications. She was discharged in good general conditions.

At a follow-up visit after 1 month, her clinical presentation was normal; blood exams were normal with resolution of anemia and normalization of eosinophils and platelets count, and stool microscopic examination was negative.

\section{Discussion}

Hookworm human infection is a public health problem, especially among rural areas of developing countries. The burden of hookworm infection is primarily related to the impact on health and quality of life. In infancy this is the consequence of a chronic infection, which may adversely affect growth, nutritional status and cognitive capacity [11].

After the direct percutaneous invasion of infective larvae from contaminated soil, at the end of their life cycle, adult worms parasite the upper small intestine and use cutting organs to suck arteriolar and capillary blood of the intestinal mucosa. In moderate and severe disease, this can lead to iron-deficiency anemia, particularly in high-risk subjects, such as young women of childbearing age and children $[6,12]$.

While most of the cases are asymptomatic, occasionally the infection can cause overt gastrointestinal bleeding and maelena, as reported also in infants from endemic areas $[7,13]$. Long term consequences are both iron deficiency anemia and protein malnutrition, with subsequent growth stunting and decreased cognitive capacity, especially working memory [14]. Among the other classical manifestations there are gastrointestinal 

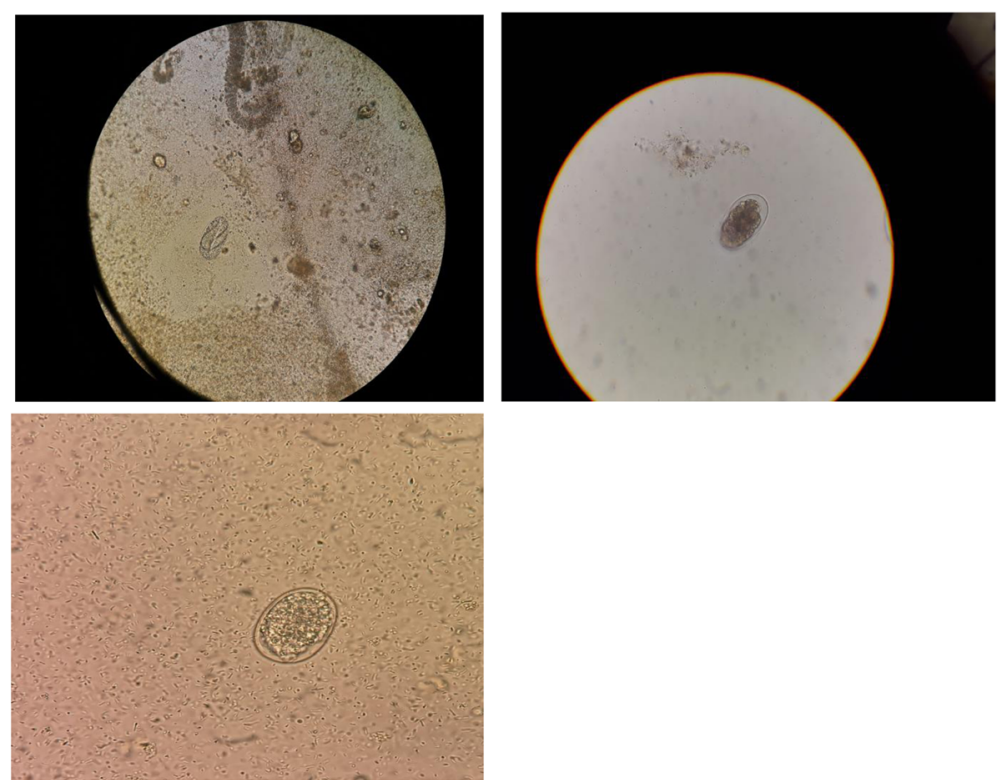

Fig. 1 Fresh microscopical analysis of the stools showing eggs of Ancylostoma duodenale

disorders, as abdominal pain, tenderness, diarrhea and vomiting. Less commonly hookworms may cause ground itch and eosinophilic pneumonia [1].

Hookworm helminthiasis remains a major cause of morbidity in infants and children in the tropics and subtropics. In contrast, it is rarely described in developed countries, and little is known about its incidence in the Italian population [15].

These infections are considered uncommon in local children, but only few studies had reported epidemiological data on the diffusion of intestinal parasitic disease Italian country, always considering together children and adults [16-20].

According to a six-years retrospective analysis performed in Ancona on 5323 adults and children [16], helminths were found in $0.9 \%$ of the subjects, with a higher prevalence in children, both in Italian and non-Italian patients. Hymenolepis nana, Strongyloides stercoralis and Trichuris trichiura were the most common species identified in non-Italian children, suggesting that certain parasites are restricted to endemic tropical areas. Another study [17] conducted on 5351 patients over a two-years period in Rome found a similar prevalence of helminth infections $(0,5 \%)$, higher in non-Italian subjects, considering both children and adults. Infection rate was low in children under 5 years of age, reaching a pick between 5 and 14 years and then declining progressively.

Overall, these findings confirm that intestinal parasites are not limited to endemic areas but can be found also in Italian country, although uncommon in natives. In support of this evidence, a recent Italian study [21] involving 584 internationally adopted children showed that intestinal parasites represent a widespread infection in these subjects, especially in school-age children. Data analysis revealed a positive association between parasitic infection and age - with a higher prevalence in children between 2 and 5 years old, that increased over 5 years of age - country of origin and eosinophilia.

According to literature helminthic infections are uncommon in local children, anyway, they should be suspected at any age, especially when clinical findings are supported by epidemiological data. Indeed, their presence in children in Italy can be explained by the increased number of travels abroad, imports of food, immigration, and adoptions.

In newborns and infants, the exact mechanism of infection still remains unclear. For those subjects who become symptomatic before the age of 5-8 weeks, a vertical transmission should be considered. Indeed, clinical reports from endemic countries assess the possibility of a vertical transmission of dormant larvae through breastfeeding or rarely transplacentally [8]. Conversely, in older children, the infection is often acquired from contaminated soil, or occasionally through larva-infested waters [10].

Although we cannot be certain of the route of contamination in our patient, it is unlikely that the infant acquired it from the environment. In fact, she lived in Italy since her born, she was from a high socioeconomic background and we were not able to detect the presence of parasites in parents' stools. The family had no accompanying animals and given her age, the acquisition through contaminated soil seemed unlikely as well. 
Considering the history of a travel in an endemic country during pregnancy and the concomitant occurrence of gastrointestinal symptoms in the mother, we assumed a transplacental transmission of Ancylostoma duodenale.

In our case, the patient showed a persistent increase in eosinophil counts on peripheral blood. This occurs with worms that have continuous tissue invasion and contact with immune effector cells, such as hookworms [14]. Therefore, an unexplained persistent eosinophilia may be a major clue for the presence of a parasitic infection and could justify specific investigations on stools.

Ova/larvae detection in stools is diagnostic, but the correct nematode identification may be challenging. In fact, microscopical diagnosis is influenced by the type of organism, its life cycle and the amount of egg or larval shedding [22]. Furthermore, the eggs of $A$. duodenale and $N$. americanus are indistinguishable at the microscopic observation [3]. Molecular methods can overcome these potential obstacles. In particular, RT-PCR provides an increased detection rate and a significantly higher specificity, enabling the distinction between the different species [22], which is helpful also to choose the appropriate therapy, considering the potential variation in the response to chemotherapeutic intervention [23].

Literature provides little information about the use of antielminthic drugs under 24 months of age. Globally, the use of benzimidazoles with different protocols (albendazole $400 \mathrm{mg}$ single dose, or mebendazole 500 $\mathrm{mg}$ single dose, or mebendazole $100 \mathrm{mg}$ twice daily for 3 days) is recommended for individual treatment [1], although more doses of albendazole may be needed to control the infection [24]. Sides effects of these drugs are rare and mostly represented by abdominal pain, nausea and diarrhea; however, the safety in children under 12 months has not been established yet [1]. A recent study on the use of mebendazole in 45 breastfeeding mothers found no adverse effects in infants [25], but so far only a few studies investigated the effects of its use directly on infants [26]. Current knowledge shows that the incidence of side effects linked to benzimidazole drugs in young children is likely to be the same as in older children and adults [27]. Therefore, in light of the potential benefit on physical and cognitive development, the treatment of young infants could be justified. Anyway, wider studies are needed to confirm these data.

In conclusion, although hookworm infections are infrequent in developed countries, they should be taken into account in children with abdominal symptoms and unexplained persistent eosinophilia. A vertical transmission has been postulated for newborns and infants, and a history of travel in an endemic country during pregnancy should always be investigated. Morphological identification of hookworms is difficult, therefore molecular methods could be useful tools for the correct diagnosis. Currently, no guidelines are available for the treatment and the follow-up of young infants. Despite the potential benefit of a treatment, further studies are needed to define the best clinical management of these cases.

\section{Acknowledgements}

Not applicable.

Authors' contributions

All authors read and approved the final manuscript.

Funding

Not applicable.

Availability of data and materials

Not applicable.

Ethics approval and consent to participate

Not applicable.

\section{Competing interests}

The authors declare that they have no competing interests.

\section{Author details}

${ }^{1}$ Università degli Studi di Milano, Milan, Italy. ${ }^{2}$ Fondazione IRCCS Ca' Granda Ospedale Maggiore Policlinico, Milan, Italy. ${ }^{3}$ Department of InfectiousTropical Diseases and Microbiology, IRCCS Sacro Cuore Don Calabria Hospital, Verona, Negrar, Italy. ${ }^{4}$ Department of Veterinary Medicine, University of Cambridge, Cambridge, UK. ${ }^{5}$ Tropical Pediatric Unit, IRCCS Ospedale Sacro Cuore Don Calabria, Verona, Negrar, Italy. ${ }^{6}$ Laboratory of Clinical Chemistry and Microbiology, ASST Melegnano and Martesana, Milan, Italy.

Received: 30 October 2020 Accepted: 2 February 2021

Published online: 09 February 2021

\section{References}

1. Jourdan PM, Lamberton PHL, Fenwick A, Addiss DG. Soil-transmitted helminth infections. Lancet. 2018;391:252-65.

2. Inpankaew T, Schär F, Dalsgaard A, Khieu V, Chimnoi W, Chhoun C, et al. High prevalence of Ancylostoma ceylanicum hookworm infections in humans, Cambodia, 2012. Emerg Infect Dis. 2014;20:976-82.

3. Hotez PJ, Brooker S, Bethony JM, Bottazzi ME, Loukas A, Xiao S. Hookworm infection. N Engl J Med. 2004:351:799-807.

4. Silver ZA, Kaliappan SP, Samuel P, Venugopal S, Kang G, Sarkar R, Ajjampur SSR. Geographical distribution of soil transmitted helminths and the effects of community type in South Asia and South East Asia - a systematic review. PLoS Negl Trop Dis. 2018;12(1):e0006153.

5. Bartsch SM, Hotez PJ, Asti L, Zapf KM, Bottazzi ME, Diemert DJ, Lee BY. The global economic and health burden of human hookworm infection. PLoS Negl Trop Dis. 2016;10:e0004922.

6. Brooker S, Bethony J, Hotez PJ. Human hookworm infection in the $21 \mathrm{st}$ century. Adv Parasitol. 2004;58:197-288.

7. Budhathoki S, Shah D, Bhurtyal KK, Amatya R, Dutta AK. Hookworm causing melaena and severe anaemia in early infancy. Ann Trop Paediatr. 2008;28(4): 293-6.

8. Yu SH, Jiang ZX, Xu LQ. Infantile hookworm disease in China. A review. Acta Trop. 1995;59:265-70.

9. Otaigbe BE, Eneh AU, Oruamabo B. Hookworm infestation in a 3-month old female. Niger J Med. 2005:14:227-30.

10. Bhatia V. Manoja Kumar Das, Pawan Kumar And Narendra Kumar Arora, Infantile Hookworm Disease. Indian Pediatr. 2010:47(2):190-2.

11. Savioli L, Albonico M, Daumerie D, Lo NC, Stothard JR, Asaolu S, Tchuem Tchuenté LA, Anderson RM. Review of the 2017 WHO Guideline: Preventive chemotherapy to control soil-transmitted helminth infections in at-risk population groups. An opportunity lost in translation. PLoS Negl Trop Dis. 2018;12(4):e0006296 
12. Papier K, Williams GM, Luceres-Catubig R, Ahmed F, Olveda RM, McManus DP, Chy D, Chau TN, Gray DJ, Ross AG. Childhood malnutrition and parasitic helminth interactions. Clin Infect Dis. 2014;59:234-43.

13. Walker AC, Bellmaine SP. Severe alimentary bleeding associated with hookworm infestation in Aboriginal infants. Med J Aust. 1975;1(24):751-2.

14. Jill E, Weatherhead, Hotez PJ. Worm Infections in Children. Pediatr Rev. 2015;36:341.

15. Peruzzi S, Gorrini C, Piccolo G, et al. Prevalence of intestinal parasites in the area of Parma during the year 2005. Acta Biomed. 2006;77(3):147-51.

16. Silvestri C, Greganti G, Arzeni D, Morciano A, Castelli P, Barchiesi F, Cirioni O, Giacometti A. Intestinal parasitosis: data analysis 2006-2011 in a teaching hospital of Ancona, Italy. Infez Med. 2013;21 (1):34-9.

17. Masucci L, Graffeo R, Bani S, Bugli F, Boccia S, Nicolotti N, Fiori B, Fadda G, Spanu T. Intestinal parasites isolated in a large teaching hospital, Italy, 1 may 2006 to 31 December 2008. Euro Surveill. 2011:16(24):19891.

18. Guidetti C, Ricci L, Vecchia L. Prevalence of intestinal parasitosis in Reggio Emilia (Italy) during 2009. Infez Med. 2010;18(3):154-61.

19. Grande R, Ranzi ML, Restelli A, Maraschini A, Perego L, Torresani E. Intestinal parasitosis prevalence in outpatients and inpatients of Cã Granda IRCCS Foundation - Ospedale Maggiore Policlinico of Milan: data comparison between 1984-1985 and 2007-2009. Infez Med. 2011;19(1):28-38.

20. Bartolini A, Zorzi G, Besutti V. Prevalence of intestinal parasitoses detected in Padua teaching hospital, Italy, march 2011 - February 2013. Infez Med. 2017; 25(2):133-41.

21. Buonsenso D, Graffeo R, Scarlato L, Acampora A, Grotti G, Scarlato L, Pata D, Colonna AT, Salerno G, Colussi L, Masucci L, Valentini P. Intestinal parasitic infections in internationally adopted children: a 10-year retrospective study. Pediatr Infect Dis J. 2019;38(10):983-9.

22. Mejia R, Vicuna Y, Broncano N, Sandoval C, Vaca M, Chico M, Cooper PJ, Nutman TB. A novel, multi-parallel, real-time polymerase chain reaction approach for eight gastrointestinal parasites provides improved diagnostic capabilities to resource-limited at-risk populations. Am J Trop Med Hyg. 2013;88:1041-7.

23. Reynoldson JA, Behnke JM, Pallant L, Macnish MG, Gilbert F, Giles S, Spargo RJ, Thompson RC. Failure of pyrantel in treatment of human hookworm infections (Ancylostoma duodenale) in the Kimberley region of north West Australia. Acta Trop. 1997;68:301-12.

24. Adegnika AA, Zinsou JF, Issifou S, Ateba-Ngoa U, Kassa RF, Feugap EN, Honkpehedji YJ, Dejon Agobe JC, Kenguele HM, Massinga-Loembe M, Agnandji ST, Mordmüller B, Ramharter M, Yazdanbakhsh M, Kremsner PG, Lell B. Randomized, controlled, assessor-blind clinical trial to assess the efficacy of single- versus repeated-dose albendazole to treat Ascaris lumbricoides, Trichuris trichiura, and hookworm infection. Antimicrob Agents Chemother. 2014;58:2535-40.

25. Karra N, Cohen R, Berlin M, Dinavitser N, Koren G, Berkovitch M. Mebendazole use during lactation: a case series report. Safety Drugs R D. 2016;16(3):251-4.

26. Montresor A, Stoltzfus RJ, Albonico M, Tielsch JM, Rice A, Chwaya HM, Savioli L. Is the exclusion of children under 24 months from anthelminthic treatment justifiable? Trans R Soc Trop Med Hyg. 2002;96:197-9.

27. Montresor A, Awasthi S, Crompton DW. Use of benzimidazoles in children younger than 24 months for the treatment of soil-transmitted helminthiasis. Acta Trop. 2003;86(2-3):223-32.

\section{Publisher's Note}

Springer Nature remains neutral with regard to jurisdictional claims in published maps and institutional affiliations.

Ready to submit your research? Choose BMC and benefit from:
- fast, convenient online submission
- thorough peer review by experienced researchers in your field
- rapid publication on acceptance
- support for research data, including large and complex data types
- gold Open Access which fosters wider collaboration and increased citations
- maximum visibility for your research: over 100M website views per year
At BMC, research is always in progress.
Learn more biomedcentral.com/submissions

